\title{
Organizational Forgetting and its Causes: an Empirical Research
}

Full name: Vicenc Fernandez

Affiliation: Universitat Politecnica de Catalunya

E-mail: vicenc.fernandez@upc.edu

International address: Colom, 11, 08222 - Terrassa (SPAIN)

Telephone: +34 937398025 - Fax: +34 937398101

Biography: Vicenc Fernandez is lecturer in the Department of Management at Technical University of Catalonia. He received a Ph.D. in organizational absorptive capacity. He has been a visiting researcher at Newcastle University, UK. His research interests include organizational knowledge, organizational communication and decision making.

Full name: Albert Sune

Affiliation: Universitat Politecnica de Catalunya

E-mail: albert.sune@upc.edu

International address: Colom, 11, 08222 - Terrassa (SPAIN)

Telephone: +34 937398025 - Fax: +34 937398101

Biography: Albert Sune is lecturer in the Department of Management at Technical University of Catalonia. He holds a Ph.D. degree in organizational learning. He has been a visiting researcher at INCAE Business School, CR. His research interests include organizational learning and forgetting. 


\title{
Organizational Forgetting and its Causes: an Empirical Research
}

\begin{abstract}
Purpose - To determine the impact of organizational forgetting on knowledge-intensive firms and the circumstances in which the loss of distinctive knowledge takes place.

Design/methodology/approach - The empirical research consisted of a qualitative proposal based on two case studies in Higher Education involving situations of organizational forgetting.

Findings - A framework for conceptualising organizational forgetting. Moreover, the results of the case study analysis include a categorization of organizational forgetting and a set of propositions about their causes.

Originality/value - Scientific research on knowledge management has focused on the processes of knowledge creation, use and transfer, but has devoted little attention to the processes of knowledge degradation and destruction.
\end{abstract}

Article Type: Research paper

Keyword(s): Organizational unlearning; Organizational forgetting; Knowledge destruction; Knowledge change; Knowledge stocks and flows 


\section{Introduction}

The knowledge-based view holds that a firm can be conceptualized as an institution for integrating knowledge (Grant, 1996). Based on works by Dierickx and Cool (1989), DeCarolis and Deeds (1999) and others, organizational knowledge can be represented as stocks of knowledge that grow through flows of increasing knowledge (organizational learning) and shrink through flows of depreciating knowledge (organizational forgetting). Scientific research on knowledge management has focused on the processes of knowledge creation, use and transfer, but has devoted little attention to the processes of knowledge degradation and destruction.

Since the 1970s and 1980s, the subject of organizational forgetting has been studied by a small number of researchers working in the areas of operations and organization theory. This divergence has engendered two disparate and by no means heterogeneous academic streams on the phenomenon of organizational forgetting. A study of the literature on the subject leads to two questions: what causes the processes of organizational forgetting? and under what circumstances does it occur?

Firstly, our paper compiles and unifies the literature produced by the two academic streams to provide a new starting point for research into the phenomenon of organizational forgetting. Secondly, the paper sets out an empirical study based on the analysis of two cases in the field of university education. As a result of this study, we propose a categorization of four types of organizational forgetting based on the codifiability of knowledge (Zander and Kogut, 1995) and the intentionality of the forgetting process (Martin and Phillips, 2003). Finally, the results of our research provide a set of propositions that may explain the possible causes of organizational forgetting. 


\section{Theoretical framework}

Knowledge stocks and flows

Organizational knowledge may be conceptualized as stocks of knowledge and flows of knowledge or information (Dierickx and Cool, 1989; DeCarolis and Deeds, 1999). This concept is based partly on prior research into information processing and organizational design (e.g. Galbraith, 1973). Since then, both elements (stocks and flows of knowledge) have been central issues in numerous research areas, such as the resource-based view (Barney 2001), the examination of capabilities (Eisenhardt and Martin, 2000; Zander and Kogut, 1995), the information view of new product development (Ancona and Caldwell, 1992) and organizational learning (Bontis, Crossan and Hulland, 2002; Huber, 1991).

Stocks of knowledge are described as the accumulation of knowledge assets within a firm, while flows of knowledge represent the streams of knowledge that move between different parts of a firm, or between external agents and the firm, and that can be assimilated and transformed into stocks of knowledge (DeCarolis and Deeds, 1999). There are alternative definitions of the concept of knowledge flow, such as those put forward by Darr, Argote and Epple (1995), Szulanski (1996) and Schulz (2001), although they all link the flow of knowledge to the movement and use of the stock of knowledge. Flows of knowledge have been classified as (1) horizontal or vertical (Gupta and Govindarajan, 2000; Schulz, 2001); (2) internal or external (Kyriakopoulos and Ruyter, 2004); and (3) input or output (Gupta and Govindarajan, 2000).

Dierickx and Cool (1989) introduced a different classification of knowledge flows using the bathtub metaphor. According to this example, the stock of water is indicated by the level of 
water in the tub and its level will depend on the flows of water into the tub (through the tap) and the flows of water out of the tub (through a leak). Using this metaphor, Dierickx and Cool (1989) posit that a firm's stock of knowledge can be increased by flows of additional knowledge or diminished by depreciating knowledge flows, that is, flows of organizational forgetting.

\section{Organizational forgetting}

Organizational forgetting has been defined as the intentional or unintentional loss of organizational knowledge at any level (Martin and Phillips, 2003). The earliest contributions by Wickelgren (1976) and Anderson (1985) were developed in the area of operations and based on the study of the degradation of knowledge due to interruptions in the production process. In the field of organization theory, researchers developed the concept of unlearning as an intentional process of discarding obsolete and misleading knowledge (Hedberg, 1981:3). Other authors considered unlearning as a required process to erase dominating ideas in order to become receptive to new ones. "Before organizations will try new ideas, they must unlearn old ones by discovering their inadequacies and then discarding them” (Nystrom and Starbuck, 1984: 53). Following these initial contributions, organizational forgetting has been studied mainly from two standpoints. The first standpoint sees accidental or unwanted forgetting as a degradation of the stocks of organizational knowledge. The second standpoint considers forgetting as an intentional process of unlearning preceding organizational learning.

In the first academic stream, the research carried out by Smunt and Morton (1985) and Smunt (1987) reasserted that the "forgetting” or the depreciation of knowledge has far-reaching implications on production programming and planning. The quantitative study by Argote, Beckman and Epple (1990) on the modelling of learning curves broke with the assumption 
that experience accumulated indefinitely (assessed as accumulated units produced), and confirmed empirically that knowledge acquired in production depreciates quickly. Later research has quantified the value of the depreciation of knowledge in production, with widely varying results. Darr, Argote and Epple (1995) concluded that just $47.4 \%$ of the stock of knowledge at the beginning of the month was maintained at the end of the month in pizza franchises. Epple, Argote and Murphy (1996) gave similar results in the automotive industry. Benkard (2000) found that $61 \%$ of the stock of experience of a firm that manufactured airplanes was retained in the course of one year. Other experiential studies in the automotive industry analysed longitudinally the learning results of improvement programmes (Carmona and Grönlund, 1998). They found that teams initial learning was supported by intrinsic motivation but when it disappeared, organizational learning became organizational forgetting. The overall conclusion was that forgetting has a negative impact on production capacity, productivity or product quality and that it should therefore be prevented.

By contrast, the second academic stream examines intentional forgetting as a preliminary step to organizational learning: "learning often cannot occur until after there has been unlearning” (Starbuck, 1996). This view argues that certain routines, rules, tasks, roles, policies, values and strategies need to be forgotten before new organizational knowledge can be acquired and assimilated (Lei, Slocum and Pitts, 1999). Forgetting is thus viewed as a necessary process for the management of change (Akgün et al., 2007). According to Martin and Phillips (2003), the forgetting process is just as important as the organizational learning process for achieving a sustainable competitive advantage. Several ways of forgetting intentionally were described in previous studies. Nystrom and Starbuck (1984: 58) suggest that the way to unlearn during an organizational crisis is by removing top managers as a group. This is because top managers are bolstered by previous successes and adamantly cling to their beliefs and perceptions 
therefore rationalizing their organizations' failures. Change in ownership is often another trigger of forgetting (Markoczy, 1994). When an organization is acquired by another, some restructuring in the acquired company takes place in order to align its routines and processes. Finally, Martin and Phillips (2004), describe purposeful modes of organizational forgetting related to international alliances in the tourism industry. In this field research the authors describe several examples of voluntary forgetting directly transcribed from interviews.

\section{Methodology}

Theory-building research using cases typically answers research questions that address "how" and "why" in unexplored research areas. To determine the impact of organizational forgetting and the circumstances in which this takes place, we used qualitative data due to its ability to explicate the complex social processes involved. Multiple cases create more robust theory because the propositions are more deeply grounded in varied empirical evidence (Eisenhardt and Graebner, 2007). To this end, we proposed an exploratory study based on two case studies in Higher Education involving situations of organizational forgetting.

The cases consist of a longitudinal study of two Engineering degree subjects, which were taught at a European Public University. These subjects were selected for their representation in the degree, for the easy access to the staff that developed these subjects and for the large amount of secondary sources of information that they offered. Subject A was a compulsory subject worth 4.5 credits (45 class hours) taken during the first year of an Engineering degree course, taught on a semi-distance basis during the fall semester. Subject B was a compulsory subject worth 6 credits (60 class hours) taken during the second year of an Engineering course, which was taught on a face-to-face basis during the spring semester. Both subjects involved 8 lecturers and a thousand of students during the research period. The data were 
gathered in the last semester of 2006 and centred in the forgetting processes that had taken place from their creation in 1998 to 2006.

The information required to carry out a study of this nature was not readily available from secondary sources. We therefore collected information from primary sources through several focused interviews on different interest groups. Before collecting these data, we analyzed some secondary information sources (e.g. the lecturer assignment tables and the course guides) in order to identify everyone that had been involved in the two cases during the research period. Moreover, we carried out two pilot interviews of an open-ended nature with a coordinator and a lecturer which allowed us to build the structure and the main topics of the interviews (the staff, teaching materials, students, methodologies used, the learning tools, and the required knowledge to carry out the course) and a set of questions for the following interviews. Both respondents also suggested other people to interview (e.g. former coordinators and some specific students and the Vice-President for Academic Innovation), and some other secondary sources of evidence (e.g. documentation about students' complaints). The following interviews were personal and private, following a semi-structured script, where we asked them for a short period of time - around an hour - about the evolution and the development of the subject according to the previous topics, as well as their opinions about these events. To increase the reliability of interviews and observational evidence, both authors carried out the interviews together. Finally, we interviewed twelve lecturers and professors involved in both cases during the analyzed period, four course coordinators, the Vice-President for Academic Innovation and a sample of selected students according to some lecturers' suggestions. In some cases, we had to interview informants on several occasions due to conflicting events (e.g. the reasons for modifying some course teaching materials) and new events that we identified after the first interview (e.g. time dedicated to prepare a session). We 
realized that some informants had not detected loss of knowledge up to the interview due to the fact that they had not considered it before.

We collaborated interviews data with information from other secondary sources in order to avoid bias, poor recall and poor or inaccurate articulation. Moreover, these secondary sources allowed us to complement, to some degree, the lack of information obtained from the interviews (e.g. some changes in course teaching materials). Finally, we gathered information from the following historical documents: teaching guides, course guides, course evaluation questionnaires, lecturers assignation tables, students' complaints, slide collections and teaching handbooks. These documents allowed us to identify, mainly, changes in teaching materials and the goals of the subjects (e.g. a new version of the textbook and new topics in the course contents). These secondary sources of information were used to triangulate the validity of our findings (Eisenhardt, 1989).

\section{Analysis}

We gathered a huge amount of data from the previous information sources, so we reduced and processed it following the strategies proposed by Miles and Huberman (1994). The reduction of the data was made by means of successive codifications of the collected data from the interviews and the historical materials. This codification permitted us to reduce this large amount of data into a smaller number of analytic units. The process used to reduce the data followed a two-level schema. Firstly, we built a general accounting scheme for codes in order to structure the gathered data. This scheme, which followed the suggestions of Lofland (1971), was made up by acts (e.g. change of the textbook), activities (e.g. teaching methodologies), meanings (e.g. comments about the results of the course), participation (e.g. students and teachers' behaviour), relationships (e.g. working atmosphere), settings (e.g. kind 
of studies: distance versus non-distance), strategies (e.g. goals of activities and acts) and methods (e.g. the time lost feeling). The second level was more specific and related to the objective of the research. To achieve the aim of answering the research questions, the pattern coding of data at this level centred on identifying all the fragments that referred to the acquisition and loss of knowledge in each case, as well as all codified elements involved in these processes including the possible specific causes and consequences of this acquisition or loss of knowledge. This step of codification took a great deal of time due to problems in differentiating between the processes of forgetting and their causes (e.g. lecturer's turnover versus knowledge embodied in this lecturer), and we even had to gather complementary data on certain occasions through two new interviews to complete the context where a loss of knowledge took place (e.g. a reason to change the course intranet).

\section{Within-Case Analysis}

Following the suggestions of Miles and Huberman (1994), we carried out a Within-Site Analysis of every case in order to display an organized and compressed assembly of codified information that allows for conclusion drawing and subsequent action. Firstly, we developed a checklist matrix to coherently organize several components for every case. These matrices showed the different sources of data in rows and the topics or codes (both the codes from the first step and the second step) in columns. The matrices allowed us to display the information sources of the codified elements and their reliability and importance according to the number of sources that corroborated them. Again, we gathered complementary data to check some events due to the fact that they came from only one secondary information source (e.g. updating of the slide collection). From each matrix, we generated a Time-Ordered Matrix that showed the several organizational processes throughout the study period. From the matrices, we re-analyzed the forgetting of organizational knowledge that we had identified previously. 
As a result of the former analysis, some events, which had been codified as forgetting processes, were erased due to lack of clear evidence.

As a result, as many as 10 situations could be singled out in which the forgetting of organizational knowledge occurred in the first case study (Subject A). Brief descriptions of these situations are listed in the following list.

- OF1: Change of teaching methodology used by lecturers: face-to-face teaching skills were replaced by distance teaching skills in 2000.

- OF2: Loss of the specific technical knowledge embodied in the coordinator due to him leaving unexpectedly in 2003.

- OF3: Loss of dynamics in the way in which the course was run and managed due to a change in coordinator in 2003.

- OF4: Loss of the teaching material because the former coordinator didn't leave any own written document in 2003.

- OF5: Replacement of all the teaching materials used previously due to a redesign of the course in 2005.

- OF6: Amount of time dedicated to re-prepare the classroom sessions due to the length of time between two consecutive courses.

- OF7: The experience gained by lecturers in classroom sessions was not used in the following academic year.

- OF8: Closure of the teaching intranet and opening of a new intranet due to a new Software University Policy in 2006.

- OF9: Change in lecturers' teaching methodology in 2006: distance teaching skills focusing on self-training were replaced by skills based on group learning due to the available tools in the new intranet. 
- OF10: Replacement of part of the teaching materials due to the characteristics of the new intranet in 2006.

In the second case study (Subject B) we identified up to 9 instances of forgetting of organizational knowledge.

- OF11: Loss of specific technical knowledge embodied in the coordinator when he left the course in 1999.

- OF12: Change of teaching methodology applied by lecturers in 2002: change in the teaching skills needed for teaching a more lecture-oriented subject, according to the perspectives and style of the new coordinator.

- OF13: Updating of the slide collection, involving the elimination of $30 \%$ of existing materials per year.

- OF14: Elimination of $100 \%$ of the news articles to be commented on by students at the end of each course.

- OF15: Replacement of the book of scientific papers with a collection of selected scientific articles in 2001.

- OF16: Replacement of $75 \%$ of case studies to improve the consistency between the lectures on concepts and the discussion of case studies in 2003.

- OF17: Replacement of the complete collection of case studies with a book of cases to make the materials more accessible to students in 2004.

- OF18: Replacement of the textbook with a new revised edition in 2004.

- OF19: Projects and presentations prepared by students discarded at the end of each course. 
After the Within-Case Analysis, we carried out a Cross-Case Analysis in order to enhance generalizability and to deepen understanding and explanation of the forgetting processes. Following a code-oriented strategy, we developed a Case-Ordered Effects Matrix (based on Miles and Huberman, 1994), which had the forgetting processes we had identified before in the rows and the consequences and the rest of the coded data related to these processes (participants, settings, relationships, etc.) in the columns. Clustering the forgetting processes according to similar or equivalent consequences, we analyzed the rest of the data from these processes (e.g. roles of participants, sources of decisions, changes and kinds of knowledge) in order to identify shared elements. To achieve this goal, the analysis was made by means of successive attempts of trial and error from the gathered data.

Finally, we only obtained two shared characteristics to forgetting processes with similar consequences: the nature of the organizational knowledge and the intentionality of the process. Both characteristics explained all forgetting processes. Moreover, these results agree with the existing literature in other fields. On the one hand, Argote, McEvily and Reagans (2003) suggested that knowledge properties affect the rate at which knowledge is accumulated, how much is retained, where it is retained and how easily it diffuses within and across firm boundaries. From the existing literature and the results of our study, we could therefore consider that the features of organizational knowledge might be the primary determining factors of organizational forgetting. In this line, Saviotti (1998) suggested that the characteristics of knowledge flows (that we called learning and forgetting) depend on the type of stock of knowledge being considered. On the basis of this analysis, we took into account the nature of the organizational knowledge in its codifiability dimension; however, other authors have proposed to classify stocks of knowledge on the basis of other features (Winter, 1987; Nonaka, 1991, 1994; Zander and Kogut, 1995). Codifiability captures the degree to 
which knowledge can be encoded, even if the individual operator does not have the facility to understand it (Zander and Kogut, 1995). To operationalize this dimension, we took the codifiability dimension as a dichotomy (codified/non-codified). This classification not only makes use of the fact that knowledge is explicit and articulable (Winter, 1987; Nonaka, 1991, 1994), but also that it has been codified and recorded on some type of medium (e.g. software, book, procedure handbook). We included tacitness (Ambrosini and Bowman, 2001) as a property of non-codified knowledge, but we also needed to include knowledge that has been expressed at some time (e.g. verbally) but not recorded on any medium (or at least with no surviving record, e.g. an oral speech, lecture or debate).

On the other hand, the intentionality dimension agrees with the two previous research streams of organizational forgetting, as shown above, in the theoretical framework. We therefore decided to classify these knowledge flows through this dimension. Along the same line, results obtained in previous research papers show significant differences in the effects of organizational forgetting in both streams of investigation. Moreover, the same definition of organizational forgetting provided by Martin and Phillips (2003) introduces this differentiation between the intentional and non-intentional forgetting. One additional comment should be pointed out in order to define the intentionality dimension: The intentionality of an action supposes a decision making process, as well as an agent to take the decision. We could not find, in the previous literature, any explicit reference to the position of this agent, nor its influence on the forgetting process. As a consequence, we had to set the boundaries of the decision making process to be able to consider whether a decision to forget is intentional or not. To be coherent with our analysis process, we decided to set the "course" as the empirical framework, and the people directly involved in it (lecturers, coordinators and students) as the agents of intentional forgetting decisions. Only when the decision to set an 
intentional forgetting process in motion was deemed to have been taken within the framework of the subject was it considered intentional. So, the decisions to forget taken by the agents directly involved in a course were considered as intentional forgetting (e.g. the replacement of teaching materials due to a redesigning of the course decided by the lecturers, or the change in the teaching methodology according to the style of the coordinator). However, we considered that the forgetting situations that were generated by changes originated outside the course boundaries were non-intentional (e.g. the closure of the teaching intranet due to a Software Policy was considered non-intentional because the decision to change the teaching intranet was taken by the Vice-President for Academic Innovation and was outside the course framework). We considered both dimensions as consistent with the taxonomies mentioned earlier and as identifying a key variable for the maintenance of organizational knowledge. Since the aim of this research was not to catalogue types of knowledge, but instead types of organizational forgetting, we believed that this classification would make the characterization of organizational forgetting and its causes more operative. So, we propose a four-type taxonomy for organizational forgetting.

Table I. Classification of types of forgetting with regard to the dimensions of intentionality and codifiability

\begin{tabular}{lcc}
\hline Codified & \multicolumn{1}{c}{ Intentional } & Unintentional \\
& $\begin{array}{c}\text { Intentional forgetting of } \\
\text { codified knowledge } \\
\text { OF5, OF13, OF14, OF15, } \\
\text { OF16, OF17, OF19 }\end{array}$ & $\begin{array}{c}\text { Unintentional forgetting of } \\
\text { codified knowledge }\end{array}$ \\
\hline & $\begin{array}{c}\text { Intentional forgetting of } \\
\text { non-codified knowledge }\end{array}$ & $\begin{array}{c}\text { Unintentional forgetting of } \\
\text { non-codified knowledge }\end{array}$ \\
& OF1, OF12 & OF2, OF3, OF6, OF7, OF9, \\
& & OF11 \\
\hline
\end{tabular}

The first type of organizational forgetting comprises the deliberate loss of the stock of 
codified knowledge. The use of new standard procedures is an example of this type of organizational forgetting. It involves the elimination of old procedure handbooks (normally codified on paper) and their replacement by new procedure handbooks. A part of the organization's stock of codified knowledge must be eliminated to introduce a new stock of knowledge. Examples of the first type of forgetting in the case studies are change or replacement of teaching materials like textbook, case studies, slides and presentations, decided to be replaced or updated by lecturers.

The second type of organizational forgetting comprises the unintentional loss of the stock of codified knowledge. Examples of this type of forgetting would be the loss of documents in a computer by mistake or breakdowns, or the loss of part of the codified knowledge held by employees when they are dismissed. In the first case, the written or codified documents are lost due to reasons beyond the organization's control. However, in the second example a decision relating to people management indirectly involves the loss of codified knowledge that employees may have had on their computers or files, and which they had not yet shared with their fellow workers. While the first example of a loss of the stock of knowledge is due to a circumstance beyond the lecturer's control (e.g. closure of a teaching intranet and opening of a new one due to a new software policy, and the replacement of old teaching materials to adapt to the characteristics of the new intranet), in the second example the loss of the stock of knowledge was caused by a publisher decision to replace the textbook with a new edition. Examples in this category are the loss of teaching materials and learning tools (teaching intranet) imposed by outsiders or by former lecturers who left the subject without having shared their codified resources.

The intentional loss of a stock of non-codified knowledge is the third type of organizational 
forgetting. An example of this type of organizational forgetting occurs in organizations in which an attempt is made to change the corporate culture; for example, by increasing the degree of employee involvement. In these situations, workers have certain beliefs as to their role in the organization that are reflected in their conduct and in certain organizational routines. This conduct and these routines are not defined or codified in any form and therefore they are difficult to identify. However, in order to attain a more participatory culture, existing beliefs and routines must be eliminated, so that they can be replaced by new beliefs, new conducts and new organizational routines. Examples of the third type of forgetting in the case studies are the evolutionary changes in methodologies and lecturers skills to improve the subjects.

Lastly, the fourth type of organizational forgetting involves the unintentional loss of a stock of non-codified knowledge. In this situation, vacation periods or the resignation of a salesperson from an organization may involve this type of organizational forgetting. Workers on production lines acquire habits and routines through daily experience that allow them to improve their performance; however, vacation periods result in a reduction of that noncodified knowledge and, consequently, a poorer performance by workers returning from their vacations. The resignation by a salesperson also involves a loss of non-codified knowledge, since the salesperson may be familiar with certain peculiarities about customers that are not recorded in any document and, consequently, a former salesperson may be more efficient than a new salesperson who lacks this knowledge. We also found several examples of this category in the case studies. Some technical knowledge, processes, routines, skills and methodologies embodied in lecturers, were lost in unexpected situations. For example, when a lecturer or a coordinator left the subject unexpectedly they took their knowledge with them. Moreover, when the teaching team remains, knowledge seemed to degrade and lecturers had to devote a 
lot of time to recover lost knowledge through preparing sessions and remembering what they have taught before. In addition, changes in the external environment turned some knowledge or teaching skills obsolete and lecturers had to adapt to the new situation, and forget previous ways of performing.

\section{Results and discussion}

In order to carry out a generalition or extrapolation, we developed a set of propositions from the empirical results of the two case studies and the existing literature on organizational forgetting. It's necessary to mention that our goal was not to make an inference about a population (or universe), but to make generalizations to theoretical propositions (Yin, 2003). We present these propositions in the following paragraphs.

Several examples of organizational forgetting show that internal innovation (innovation driven by agents who belong to the framework of analysis) is one of the main factors leading to the intentional loss of stocks of codified information. The replacement of all or a part of the teaching materials to update the specific technical knowledge on the course (OF5, OF13, OF15 and OF16) or to reduce the dispersion of teaching materials (OF17) are examples of innovation initiated and managed by the lecturers teaching the subject.

Proposition 1a: The process of intentional forgetting of codified knowledge is set in motion by the presence of internal innovation.

Another factor causing the intentional loss of stocks of codified knowledge is the obsolescence of knowledge. For example, the press articles used in Subject B (OF14) were discarded because they were no longer up-to-date and, consequently, could not fulfil their 
purpose, which was to show how the content of the subject could be used to explain the events occurring in society at the time. From the standpoint of the academic year, the projects and presentations submitted by the students were also discarded (OF19) at the end of the year, since their purpose was for the students to learn while preparing the materials rather than gaining from the results themselves.

Proposition $1 b$ : The process of intentional forgetting of codified knowledge is set in motion by the obsolescence of the knowledge.

As found in the preceding situation, one of the main factors leading to the unintentional loss of a stock of codified knowledge is innovation, although in this case it was initiated from outside the framework of analysis. We have given three examples of organizational forgetting that reflect this fact (OF8, OF10 and OF18) in the cases analyzed. The replacement of the teaching intranet (a decision taken from outside the course) led to the replacement of part of the teaching materials in use due to their incompatibility with the former intranet. In Subject $\mathrm{B}$, the textbook was replaced because a new version had been published.

Proposition 2a: The process of unintentional forgetting of codified knowledge is set in motion by the presence of innovation from outside.

In Subject A, the unplanned departure of the coordinator caused the loss of all the teaching materials used for the course (OF4) because the only copy of these materials existed on the coordinator's computer, to which the replacement did not have access. The fact that all the teaching materials were located in just one place meant that a small change gave rise to loss of the full stock of knowledge in the form of teaching materials and the need to generate this 
full stock knowledge once again from scratch. Therefore, the unintentional loss of a codified stock of knowledge is sensitive to the effectiveness of the organizational memory (Olivera, 2000).

Proposition 2b: The process of unintentional forgetting of codified knowledge is set in motion by the loss of the repository of the stock of knowledge if it is highly centralized.

The main cause of the intentional loss of a stock of non-codified knowledge is the degree of internal innovation, according to the cases studied. Two examples of organizational forgetting confirm this assertion (OF1 and OF12), and both are related to changes in the teaching methodology due to internal decisions that affect each of the courses. Given the semi-distance nature of Subject A, the coordinator decided to replace classroom teaching skills with other skills to adapt the students' learning process to the characteristics of the course. In the other case, the changes made to the teaching methodology for Subjet B led to the replacement of certain lecturing skills (2002-03 academic year) and certain participation skills (2005-06 academic year) as a result of an internal change of the course coordinator.

Proposition 3: The process of the intentional forgetting of non-codified knowledge is set in motion by the presence of internal innovation.

The innovation, initiated by the university, which involved replacing the teaching intranet, meant that the teaching skills developed up until that time had to be replaced by new teaching skills based on group learning (OF9) in Subject A. In this case, the innovation is considered external to the course because the decision was taken without the participation of its agents. 
On the basis of this example, we adduce that external innovation is a cause of the unintentional loss of the stock of non-codified knowledge, where the teaching skills that were replaced represent this stock of knowledge.

Proposition 4a: This process of the unintentional forgetting of non-codified knowledge is set in motion by the presence of external innovation.

Another cause of the unintentional loss of a stock of non-codified knowledge occurs when this knowledge is located in just one person who leaves the organization. The skills relating to the management of Subject A (OF3) were lost due to the unplanned departure of its coordinator and the loss of the specific technical knowledge embodied in the coordinators and lecturers of the two cases studied (OF2 and OF11).

Proposition $4 b$ : The process of unintentional forgetting of non-codified knowledge is set in motion by the person who embodies that knowledge on leaving the organization, if the stock of knowledge is highly centralized.

Two examples of organizational forgetting show that the repetition frequency in the use of knowledge is a possible cause of the unintentional loss of a stock of non-codified knowledge. The excessive time spent preparing classroom sessions (OF6) due to the fact that they are repeated only once yearly helps to illustrate this fact. We can assume that in situations in which a class or explanation must be repeated several times over a short period, the preparation time will gradually decrease. The ongoing non-improvement of classroom sessions in Subject A (OF7) is another example that upholds this proposition. In this case, the learning achieved by a lecturer in a classroom session had no effect on the following 
academic year, since this knowledge deteriorated over time. The solution arrived at by the coordinator was to convert it into codified knowledge by means of record sheets, so that its infrequent use would not contribute to its loss.

Proposition 4c: The process of the unintentional forgetting of non-codified knowledge is set in motion by a low frequency of repetition in the use of the knowledge.

Table II: Propositions on the causes of organizational forgetting

\begin{tabular}{lll}
\hline & \multicolumn{1}{c}{ Intentional } & \multicolumn{1}{c}{ Unintentional } \\
\hline \multirow{3}{*}{ Codified } & $\begin{array}{l}\text { Prop.1a: Internal innovation } \\
\text { Prop.1b: Obsolescence of } \\
\text { knowledge }\end{array}$ & $\begin{array}{l}\text { Prop.2a: External innovation } \\
\text { Prop.2b: Loss of a knowledge } \\
\text { repository }\end{array}$ \\
\hline & Prop.3: Internal innovation & $\begin{array}{l}\text { Prop.4a: External innovation } \\
\text { Prop.4b: Persons who embody }\end{array}$ \\
Non- & & $\begin{array}{l}\text { the knowledge leave the } \\
\text { codified }\end{array}$ \\
& & $\begin{array}{l}\text { organization } \\
\text { Prop.4c: Low frequency of use }\end{array}$ \\
\hline
\end{tabular}

\section{Conclusions}

Our research is based on the premise that the stock of knowledge held by organizations is in a state of ongoing change rather than an increasing resource. From a theoretical standpoint, this change can be attributed, on the one hand, to flows of learning that increase the stock of knowledge and, on the other hand, to flows of forgetting that reduce the stock of knowledge.

The previous literature has defined the concept of organizational unlearning (e.g. Hedberg, 1981) and organizational forgetting (e.g. Smunt, 1987); some authors have even attempted to unify these two initial academic trends (e.g. Martin de Holan and Phillips, 2004). It has also described different examples and ways to forget at an organizational level (e.g. Carmona and Grönlund, 1998; Nystrom and Starbuck, 1984). Finally, some studies have quantified the amount of lost knowledge through forgetting curves (e.g. Darr, Argote and Epple, 1995). 
However, the existing literature has paid little attention to the causes of organizational forgetting, as the low number of longitudinal field studies show. In order to identify and classify the causes of organizational forgetting, we have carried out an empirical study in higher education. This study presents an integrated framework that gives rise to a set of propositions about the causes of organizational forgetting.

On the basis of our analysis, we conclude that forgetting is closely related to innovation. When innovation is internal, the type of forgetting generated will be intentional, since the specific purpose of innovation is to abandon the use of prior knowledge. The quantity of knowledge that is renewed is determined by the speed of innovation. This speed can be slow if the intention is an exploitation of the stock of knowledge, or fast if the intention is to give priority to the exploration of new knowledge. In both case studies, we observed that the speed of innovation in Higher Education depends on the coordinator of the subject. In other contexts, this dependence would correspond to the team leader.

When innovation is external, the type of forgetting generated will be unintentional. This is the case with a type of innovation that is not managed internally by the empirical framework, but instead imposed from outside. The attitude of the agents involved in an external innovation can be proactive or reactive. In the analyzed cases, when the attitude was proactive, the agents adopted the innovation and generated a major forgetting and subsequent learning. When the attitude was reactive, the agents tried to forget the minimal stock of existing knowledge, adapting partially to the innovation, and underused it.

In addition to external innovation, the loss of the knowledge repository and the infrequent use of knowledge are identified as other causes of unintentional forgetting. The nature of the 
knowledge repository will differ, depending on whether the stock of knowledge is codified (e.g. a computer file or written document) or non-codified (e.g. employees or organizational routines). The interviewees evaluated the cost of forgetting caused by the rotation of a lecturer in two academic years. In addition, it was observed in our research that if the person who leaves the course is the coordinator or team leader, the speed of internal innovation is also affected.

The possible limitations of our work, given its nature as a piece of inductive research, are mainly connected to the fact that a small number of cases were studied. With the aim of enhancing the maturation of the research, we selected two case studies, which reported nineteen pieces of evidence, belonging to the same organization. To resolve this limitation, we suggest that the study sample be broadened to include other empirical frameworks and other business activities. In addition, it is important to highlight that there is no forgetting involved in all change processes. We found some examples of change where forgetting did not take place (e.g. introduction of podcasting in subject A); however, we did not mention it because our study has focused only on facts related to organizational forgetting.

Future lines of research could make use of the results in this paper to investigate some unanswered questions about organizational forgetting. For example, what is the knowledge life cycle like? Which strategies of organizational forgetting make sense in a process of organizational change? Which actions may be taken to forget selectively? What is the cost of unintentional forgetting? These research questions seem to us to be sufficiently suggestive as much in the academic context as in business. 


\section{References}

Akgün, A.E., Byrne, J.C., Lynn, G.S. and Keskin, H. (2007), “Organizational unlearning as changes in beliefs and routines in organizations”, Journal of Organizational Change Management, Vol. 20 No. 6, pp. 794-812.

Ambrosini, V. and Bowman, C. (2001), "Tacit knowledge: Some suggestions for operationalization", Journal of Management Studies, Vol. 38, pp. 811-829.

Ancona, D.G. and Caldwell, D.F. (1992), "Demography and Design - Predictors of New Product Team Performance”, Organization Science, Vol. 3, pp. 321-41.

Anderson, J.R. (1985), Cognitive Psychology and Its Implications, WH Freeman and Company, New York, NY.

Argote, L., Beckman, S.L. and Epple, D. (1990), “The Persistence and Transfer of Learning in Industrial Settings”, Management Science, Vol. 36, pp. 140-54.

Argote, L., McEvily, B. and Reagans, R. (2003), “Managing Knowledge in Organizations: An Integrative Framework and Review of Emerging Themes”, Management Science, Vol. 49, pp. 571-82.

Barney, J.B. (2001), "Resource-Based Theories of Competitive Advantage: A Ten-Year Retrospective on the Resource-Based View”, Journal of Management, Vol. 27, pp. 64350.

Benkard, C.L. (2000), “Learning and Forgetting: The Dynamics of Aircraft Production”, American Economic Review, Vol. 90, pp. 1034-54.

Bontis, N., Crossan, M.M. and Hulland, J. (2002), "Managing an Organizational Learning System By Aligning Stocks and Flows”, Journal of Management Studies, Vol. 39, pp. 437-69.

Carmona, S. and Grönlund, A. (1998), “Learning from Forgetting: An Experiential Study of Two European Car Manufacturers”, Management Learning, Vol. 29, pp. 21-38. 
Darr, E.D., Argote, L. and Epple, D. (1995), “The Acquisition, Transfer, and Depreciation of Knowledge in Service Organizations: Productivity in Franchises”, Management Science, Vol. 41, pp. 1750-62.

DeCarolis, D.M. and Deeds, D.L. (1999), “The Impact of Stocks and Flows of Organizational Knowledge on Firm Performance: An Empirical Investigation of the Biotechnology Industry”, Strategic Management Journal, Vol. 20, pp. 953-68.

Dierickx, I. and Cool, K. (1989), “Asset Stock Accumulation and Sustainability of Competitive Advantage”, Management Science, Vol. 35, pp. 1504-11.

Eisenhardt, K.M. (1989), "Building Theories From Case Study Research”, Academy of Management Review, Vol. 14, pp. 532-50.

Eisenhardt, K.M. and Graebner, M.E. (2007), “Theory Building From Cases: Opportunities and Challenges”, Academy of Management Journal, Vol. 50, pp. 25-32.

Eisenhardt, K.M. and Martin, J.A. (2000), “Dynamic Capabilities: What Are They?”, Strategic Management Journal, Vol. 21, pp. 1105-21.

Epple, E. and Argote, L. (1996) “An empirical investigation of the microstructure of knowledge acquisition and transfer through learning by doing”, Operations Research, Vol. 44, pp.77-86

Galbraith, J.R. (1973), Designing Complex Organizations, Addison-Wesley Longman Publising Co., Boston.

Grant, R.M. (1996), “Toward a knowledge-based theory of the firm”, Strategic Management Journal, Vol. 17, pp. 109-122.

Gupta, A.K. and Govindarajan, V. (2000), "Knowledge Flows Within Multinational Corporations”, Strategic Management Journal, Vol. 21, pp. 473-96.

Hedberg, B. (1981), "How Organizations Learn and Unlearn”, in Nystrom, P. and Starbuck, W. (Eds.), Handbook of Organizational Design, Oxford University Press, Oxford, pp. 3- 
27.

Huber, G.P. (1991), “Organizational Learning: The Contributing Processes and the Literatures”, Organization Science, Vol. 2, pp. 88-115.

Kyriakopoulos, K. and Ruyter, K. (2004), “Knowledge Stocks and Information Flows in New Product Development”, Journal of Management Studies, Vol. 41, pp. 1469-98.

Lei, D., Slocum, J.W. and Pitts, R.A. (1999), "Designing Organizations for Competitive Advantage: The Power of Unlearning and Learning”, Organizational dynamics, Vol. 27, pp. 24-38.

Lofland, J. (1971), Analysing social settings: A guide to qualitative observation and analysis, Wadsworth, Belmont, CA.

Markoczy, L. (1994), “Modes of organizational learning”, International Studies of Management and Organization, Vol. 24, pp. 5-30

Martin de Holan, P. and Phillips, N. (2003), “Organizational Forgetting”, in Easterby-Smith, M. and Lyles, M.A. (Eds.), Handbook of Organizational Learning and Knowledge Management, Blackwell, Oxford, pp. 393-409.

Martin de Holan, P. and Phillips, N. (2004), “Remembrance of things past: The dynamics of organizational forgetting” Management Science, Vol. 50, pp. 1603-1613.

Miles, M.B. and Huberman, A.M. (1994), An Expanded Sourcebook Qualitative Data Analysis, Sage Publications, London.

Nonaka, I. (1991), “The Knowledge-Creating Company”, Harvard business review, Vol. 69, pp. 96-104.

Nonaka, I. (1994), “A Dynamic Theory of Organizational Knowledge Creation”, Organization Science, Vol. 5, pp. 14-37.

Nystrom, P.C. and Starbuck, W.H. (1984), “To Avoid Organizational Crises, Unlearn”, Organizational dynamics, Vol. 12, pp. 53-65. 
Olivera, F. (2000), "Memory Systems in Organizations: An Empirical Investigation of Mechanisms for Knowledge Collection, Storage and Access”, Journal of Management Studies, Vol. 37 No. 6, pp. 811-832.

Saviotti, P.P. (1998), “On the Dynamics of Appropriability, of Tacit and of Codified Knowledge”, Research Policy, Vol. 26, pp. 843-56.

Schulz, M. (2001), “The Uncertain Relevance of Newness: Organizational Learning and Knowledge Flows”, Academy of Management Journal, Vol. 44, pp. 661-81.

Smunt, T.L. (1987), “Impact of Worker Forgetting on Production Scheduling”, International Journal of Production Research, Vol. 25, pp. 689-701.

Smunt, T.L. and Morton, T.E. (1985), “The Effects of Learning on Optimal Lot Sizes Further Developments on the Single Product Case”, IIE Transactions, Vol. 17, pp. 3337.

Starbuck, W.H. (1996), “Unlearning Ineffective Or Obsolete Technologies”, International Journal of Technology Management, Vol. 11, pp. 725-37.

Szulanski, G. (1996), “Exploring Internal Stickiness: Impediments to the Transfer of Best Practice Within the Firm”, Strategic Management Journal, Vol. 17, pp. 27-43.

Wickelgren, W.A. (1976), “Memory Storage Dynamics”, in Estes, W.K. (Ed.), Handbook of Learning and Cognitive Processes, Lawrence Erlbawn Associates, Hillsdale, NJ, pp. 321-361.

Winter, S. (1987), “Knowledge and Competence as Strategic Assets”, in Teece, D.J. (Ed.), The Competitive Challenge: Strategies for Industrial Innovation and Renewal, Ballinger, Cambridge, MA, pp. 159-184.

Yin, R. (2003), Case Study Research: Design and Methods, Third Edition, Sage Publications, London.

Zander, U. and Kogut, B. (1995), “Knowledge and the Speed of the Transfer and Imitation of 
Organizational Capabilities - an Empirical Test”, Organization Science, Vol. 6, pp. 7692. 